\title{
ADAPTATION OF THE FIBEROPTIC LARYNGOSCOPE FOR TRACHEAL, INTURATION WITH SMALL DIAMETER TUBES
}

\author{
R.W.J. FORD
}

\begin{abstract}
A ASTRACT
A simple adaptation of the fiberoptic laryngoscope is described which allows its use in intubating the trachea with small diameter (approximately $5 \mathrm{~mm} \mathrm{l.D.)}$ tracheal tubes.
\end{abstract}

KEY WORDS: EquiPMENT, Fiberoptic Laryngoscope; TECHNIQUES, difficult intubation.

THE INTRODUCTION of the fiberoptic bronchoscope into anaesthetic practice has made "the difficult intubation" considerably easier in both adults and children. ${ }^{1.3-5}$ Unfortunately, fiberoptic bronchoscopes are not yet available in all anaesthetic departments because of their high cost. A less expensive device, the fiberoptic laryngoscope, is more readily available and is adequate for most difficult intubations. ${ }^{2}$ Its large diameter $(5.8 \mathrm{~mm})$, however, precludes its use when a small diameter (less than $7.5 \mathrm{~mm}$ I.D.) tracheal tube is needed. This report describes a technique which allows the passage of a small diameter (approximately $5 \mathrm{~mm}$ I.D.) tracheal tube with the aid of a fiberoptic laryngoscope (American Optical).

A fiberoptic laryngoscope with a No. 8 French red rubber catheter attached by waterproof tape is shown in Figure 1. The tip of the catheter has been cut off to provide a lumen throughout its entire length. Note that the catheter has been attached just proximal to the laryngoscope tip in order to preserve mobility. The laryngoscope with catheter attached can be passed into the trachea through the nose or mouth after adequately anaesthetizing the nasopharynx, larynx and trachea. A cardiac catheter guide wire (Cook type TSCM) is then threaded through the rubber catheter into the trachea, where its position can be verified visually with the laryngoscope. With the guide wire in position, the fiberoptic laryngoscope and catheter are withdrawn, taking care to preserve the position of the guide wire in the trachea. Passage of a small tracheal tube over the guide wire into the trachea is then easily accomplished.

R.W.J. Ford, B.Sc., M.D., Ph.D., F.R.C.P.(C), Clinical Instructor, Department of Anaesthesia, University of British Columbia, Shaughnessy Hospital, 4500 Oak Street, Vancouver, B.C. V6H 3N1.

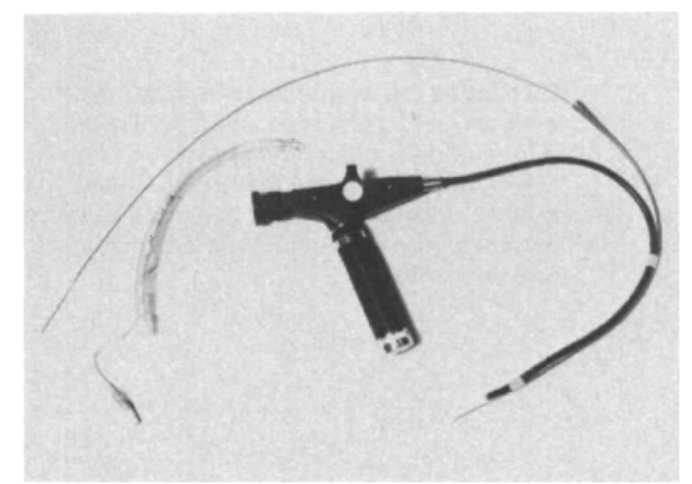

FIGURE 1 Fiberoptic laryngoscope with soft rubber catheter attached. Cardiac catheter guide wire has been passed through the catheter lumen. Following withdrawal of the laryngoscope and catheter, the tracheal tube can be passed into the trachea over the guide wire.

This technique was used to intubate the trachea of a 47 year old East Indian woman with whom we were unable to communicate because of language difficulties. She presented for correction of temporomandibular joint dysfunction under general anaesthesia. Her mouth had a maximum anterior opening of $4 \mathrm{~mm}$. After shrinking her nasal mucosa with four per cent cocaine packs it was found that the nasal passages would admit only a $6.0 \mathrm{~mm}$ tracheal tube. The patient was sedated with an intravenous injection of Innovar $2 \mathrm{ml}$. The nasopharynx was anaesthetized with a spray of $50 \mathrm{mg}$ of lidocaine. and the trachea and larynx were anaesthetized with $2 \mathrm{ml}$ of 4 per cent lidocaine by transtracheal block. Nasotracheal intubation with a $6.0 \mathrm{~mm}$ I.D. cuffed tracheal tube was then accomplished as described above. The procedure was atraumatic and well tolerated by the patient.

Intubation of the trachea with small diameter tracheal tubes is most easily accomplished using a small fiberoptic bronchoscope such as the 
Olympus BR-3C2, $3.2 \mathrm{~mm}$ diameter, as described by Alfery, et al. ' and Rucker, Silva and Worcester ${ }^{4}$. If this instrument is not available, however, the technique herein described provides a useful alternative for these otherwise difficult intubations.

\section{REFERENCES}

1. Alfery, D.D., Ward, C.F., Harwood, I.R. \& MANNINo, F.L. Airway Management for a Neo- nate with Congenital Fusion of the Jaws. Anesthesiology 51 : 340-342 (1979).

2. A pplebaum, E.L. Laryngeal and Tracheal Problems in Patients with Central Nervous System and Spinal Disorders. Otolaryngologic Clinics of N.A. 12: 829-835 (1979).

3. Messeter, K.H. \& Pettersson, K.l. Endotracheal Intubation with the Fibre-optic Bronehoscope. Anaesthesia 35: 294-298 (1980).

4. Rucker, R.W., Silva, W.J. \& Worcester, C.C. Fiberoptic Bronchoscope Nasotracheal Intubation in Children. Chest 76: 56-58 (1979).

5. TAylor, P.A. \& Towey, R.M. The BronchoFiberscope as an aid to endotracheal intubation. Brit. J. Anaesth. 44; 611-612 (1972),

\section{RÉSUMÉ}

La fixation (au moyen de sparadrap imperméable) d'un cathéter de calibre \# $8 \mathrm{FR}$. à la paroi extérieure d'un laryngoscope à fibres optiques permet l'utilisation de cet appareil pour les cas d'intubation difficile même lorsque la trachée est de petit calibre. Après visualisation du larynx une broche-guide introduite dans le cathéter est glissée sous vision directe dans la trachée et laissée en place après retrait du laryngoscope. Cette broche sert alors de guide et permet le passage de tubes de 5 à $7.5 \mathrm{~mm}$, ce qui est impossible avec le laryngoscope à fibres optiques ordinaire. 